\title{
34. CORRELATION BETWEEN MICROFOSSIL GROUPS, PANAMA BASIN, EASTERN EQUATORIAL PACIFIC
}

\author{
Menno G. Dinkelman, School of Oceanography, Oregon State University, \\ Corvallis, Oregon
}

The Panama Basin underlies a region of very complex surface circulation patterns and of generally high biologic productivity. The warm Equatorial Counter Current flows into the northern part of the basin, whereas the southern part of the basin lies within the influence of the cool, highly productive waters of the Peru Current. This contrast in oceanographic regimes within the basin is reflected in the nature of the sediments recovered at DSDP 157 and 158 .

DSDP 157 sediments are more siliceous and high in organic matter compared to those at DSDP 158, which are more calcareous. Differences between sites are also expressed by the microfossil assemblages; DSDP 158 assem- blages have a definitely more tropical aspect than those from DSDP 157.

Because the complex oceanographic conditions have left a distinct imprint on the composition of the microfossil groups, there are some problems with zonation and correlation between groups; especially for the interval above the uppermost Miocene. Thus, one should use caution in applying the biostratigraphic correlation presented in Figure 1 to sediment sequences from other parts of the world.

Specific problems with the zonation of each microfossil group are discussed in more detail in the various micropaleontologic studies reported elsewhere in this volume. 


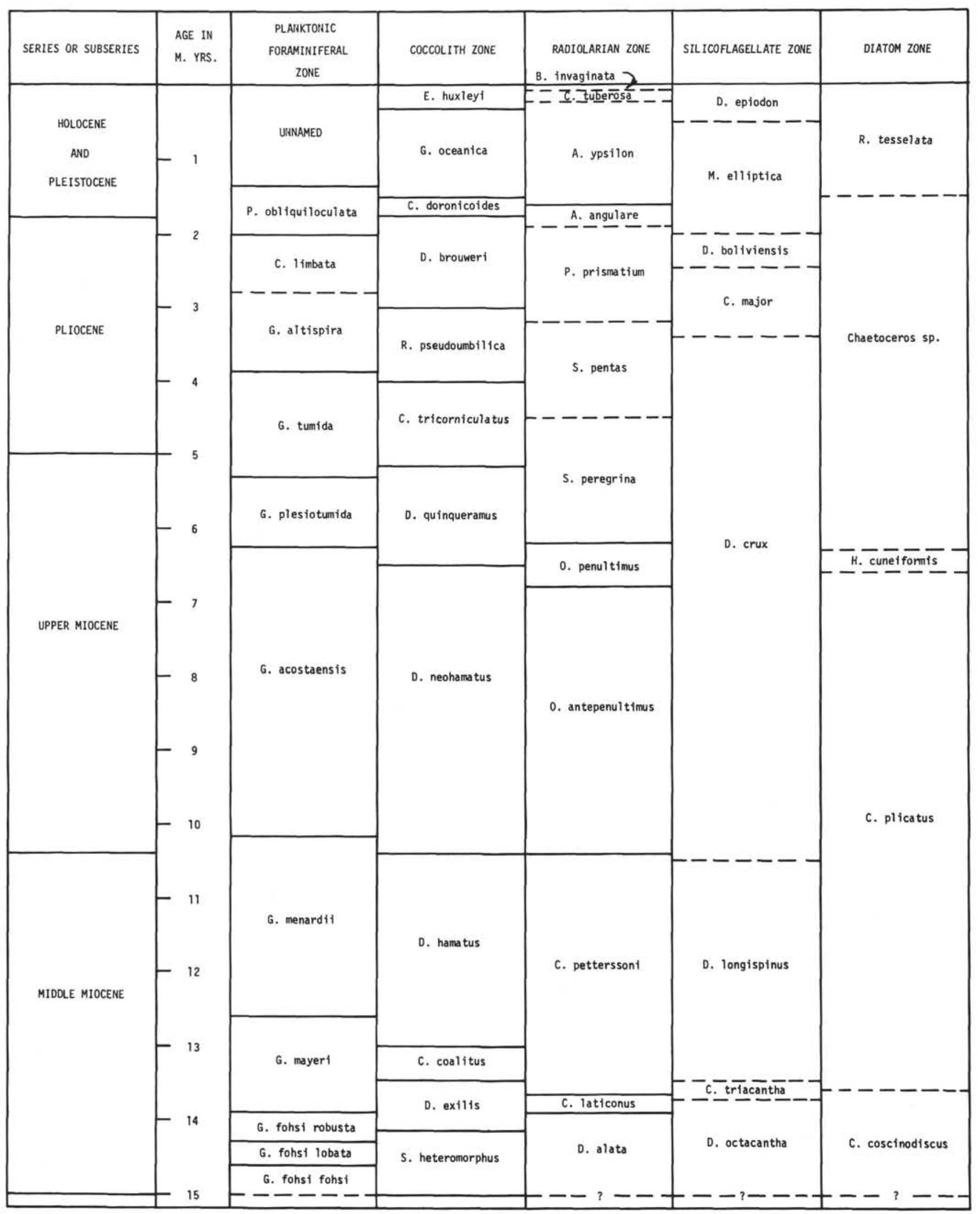

Figure 1. Biostratigraphic correlation, Panama Basin. 